The University of San Francisco

USF Scholarship: a digital repository @ Gleeson Library |

Geschke Center

Kinesiology (Formerly Exercise and Sport Science)

College of Arts and Sciences

$2-2008$

\title{
The Effects of Roster Turnover on Demand in the National Basketball Association
}

\author{
Alan L. Morse \\ Stephen L. Shapiro \\ Chad D. McEvoy \\ Daniel A. Rascher \\ University of San Francisco, RASCHER@USFCA.EDU
}

Follow this and additional works at: http://repository.usfca.edu/ess

Part of the Sports Management Commons

\section{Recommended Citation}

Morse, Alan L.; Shapiro, Stephen L.; McEvoy, Chad D.; and Rascher, Daniel A., "The Effects of Roster Turnover on Demand in the National Basketball Association" (2008). Kinesiology (Formerly Exercise and Sport Science). Paper 7.

http://repository.usfca.edu/ess/7

This Article is brought to you for free and open access by the College of Arts and Sciences at USF Scholarship: a digital repository @ Gleeson Library | Geschke Center. It has been accepted for inclusion in Kinesiology (Formerly Exercise and Sport Science) by an authorized administrator of USF Scholarship: a digital repository@ Gleeson Library | Geschke Center. For more information, please contact repository@usfca.edu. 


\title{
The Effects of Roster Turnover on Demand in the National Basketball Association
}

\author{
Alan L. Morse', Stephen L. Shapiro', Chad D. McEvoy², and Daniel A. Rascher ${ }^{3}$ \\ ${ }^{1}$ University of Northern Colorado \\ ${ }^{2}$ Illinois State University \\ ${ }^{3}$ University of San Francisco
}

Alan L. Morse is a doctoral student. His research interests include sport finance and sport marketing. Stephen L. Shapiro is a doctoral candidate. His research interests include sport finance and issues in college athletics. Chad D. McEvoy is an assistant professor of sport management and coordinator of the sport management graduate program. His research interests focus on revenue generation in commercialized spectator sport settings.

Daniel A. Rascher is the director of academic programs and an associate professor in the sport management program. His research focus includes sport economics and sport finance.

\begin{abstract}
The purpose of this study was to examine the effects of roster turnover on demand in the National Basketball Association (NBA) over a five-year period (2000-2005) and compare these results to previous research on turnover in Major League Baseball (MLB). A censored regression equation was developed to examine the relationship between roster turnover and season attendance, while controlling for other potentially confounding variables in the model. The censored regression model was used to account for the capacity constraints by forecasting the level of demand beyond capacity using information from the uncensored observations. The regression model was found to be significant with a log-likelihood statistic of 113.631. Previous attendance, current winning percentage, previous winning percentage, number of all-star players, local major sport competition, and team history were found to be significant predictors of attendance. However, the variables measuring the effects of roster turnover were not found to be significant. There were substantial differences in the effect of roster turnover on attendance in the NBA compared with MLB. In addition, these findings provide evidence for using censored regression when dealing with constrained variables. Sellouts in the NBA appear to have an effect on all of the variables in the demand model. Future research will need to be conducted to help sport managers understand the role of roster turnover in specific professional leagues and to better understand the importance of using a censored regression model.
\end{abstract}

Keywords: censored regression, demand, player movement

\section{The Effects of Roster Turnover on Demand in the National Basketball Association}

In the competitive world of the National Basketball Association (NBA), teams are trying to make player personnel moves through the draft, trades, and free agency in an effort to improve their roster. For example, the entire
Boston Celtics roster turned over between 2003-2004 and 2006-2007, with just two exceptions, Paul Pierce and Kendrick Perkins. However, the team's winning percentage stayed around 40\% (ESPN, 2007) during that time. Each year fans continue to attend games at the Fleet Center (capacity 18,624) to root for the Boston Celtics, even 
though a major portion of their roster has changed. Given the high attendance figures at the Fleet Center, which had an average attendance of 16,364 from 2003 to 2006, (ESPN, 2007) the high player turnover rate, and the lack of an increase in on-court success, it appears fans are not discouraged by regular changes in team composition. Previous research suggests a fan's familiarity with the players on the home team should increase his or her enjoyment of the game and have a positive impact on attendance (Kahane \& Shmanske, 1997). However, roster turnover continues to increase in the NBA as less successful teams attempt to emulate successful franchises in order to increase winning percentage and improve attendance figures (Nourayi, 2006). It is important to understand the potential effect this turnover has on the demand to attend NBA games.

One major factor affecting roster turnover is the implementation of free agency. The National Basketball Players Association (NBPA) won free agency in Robertson v. NBA (1975). In 1983, the NBA created a salary cap that is defined as a "soft cap" to help mitigate the concerns free agency created regarding competitive balance (Maxcy \& Mondello 2006). ${ }^{1}$ According to Maxcy and Mondello (2006), "Sport enthusiasts expressed concern that competitive balance would diminish as star players congregated to large market cities. However, the economic invariance principle rejects this notion, indicating that balance should remain unchanged" (p. 345). Rottenberg's (1956) invariance principle created the foundation for predicting the effects of league changes regarding free agency on player movement in professional sports. The invariance principle assumes that the system of free agency, which shifts the property right of the labor service from the owners to the players, will have no effect on the movement of talent and therefore will not have an effect on competitive balance. By sale or trade, players will be signed by teams in which they are most highly valued, or by marketing themselves as free agents.

It is believed the NBA is marketed as a "players' league" and star players are more marketable than teams (Gorman \& Calhoun, 1994). Red Auerbach, former coach and 1993 president of the Boston Celtics, stated the importance of marquee players in smaller markets. However, all franchises desire athletes who possess marquee status. Marquee players change the chemistry between spectators and the team. Without marquee players, people attend games because of their interest in the sport (Gorman \& Calhoun, 1994). According to Mark Tatum, senior vice president of marketing partnerships at the NBA, the advertising interest for Team USA was "tremendous" (even though TV ratings were miniscule). "A lot of the partners who signed up for USA Basketball also sponsor LeBron [James], Dwayne [Wade] and Carmelo [Anthony]," said Tatum. "For example, Coca-Cola and Gatorade are both USA Basketball sponsors, and each one has a relationship with Wade, Carmelo and James," (Ballard, 2006). According to John Cordova (2006), director of sports transaction management at Coca-Cola, "Coke uses the NBA movie-star image to sell Sprite. Not a team image."

Last season Dwyane Wade's and LeBron James' replica jerseys ranked first and second in sales. The perceived importance of specific players in the NBA adds further evidence to the notion that excessive player movement and roster turnover may have an impact on demand.

\section{Purpose of the Study}

The purpose of this study was to develop a model to measure the effect on demand due to roster turnover and the change in composition of NBA teams. There is limited empirical information on the effects of roster turnover on demand in professional sports (Kahane \& Shmanske, 1997). It is important to understand the impact player movement can have on attendance, since ticket sales are a major revenue stream for professional teams. Gate receipts in the NBA and the National Hockey League (NHL) are the single greatest source of income (Howard \& Crompton, 2004). In addition, roster turnover has been examined only in Major League Baseball. This variable may have different effects on various leagues and sports. For example, Branvold, Pan, and Gabert (1997) found that population had a significant impact on attendance at lower levels of minor league baseball, but the impact was not significant at higher levels. Findings in the majority of demand studies differ by sport and level of play (Shackelford \& Greenwell, 2005). Therefore, the demographic makeup, spectator-fan interaction, and franchise locations may be unique to each sport and each league.

The model incorporates additional variables based on previous literature to help explain a significant portion of 
Morse, Shapiro, McEvoy, Rascher

the variation in NBA attendance. Initially, both ordinary least squares (OLS) and censored regression techniques were used to explain the variability in NBA attendance. However, censored regression takes into consideration the capacity constraints on attendance, and therefore it was the most appropriate model when examining the NBA where sellouts are common.

\section{Review of Related Literature}

\section{Traditional Factors Affecting Demand}

There has been a variety of research conducted on the factors that affect attendance at sporting events. The majority of these studies have focused on Major League Baseball (Baade \& Tiehen, 1990; Greenstein, \& Marcum, 1981; Kahane \& Shmanske, 1997; McEvoy, Nagel, DeSchriver, \& Brown, 2005; Noll, 1974; Rivers \& DeSchriver, 2002). However, there have been studies conducted in professional football (Noll, 1974; Hanson \& Gauthier, 1989), college football (DeSchriver, 1999; Jensen \& DeSchriver, 2002), college basketball (McEvoy \& Morse, 2007), professional basketball (Burdekin \& Idson, 1991; Noll, 1974; Pease \& Zhang, 2001; Whitney, 1988; Zhang, Pease, Hui, \& Michund, 1995), and professional hockey (Hanson \& Gauthier, 1989; Zhang, Pease, Lee, Lam, Smith, \& Jambor, 1997).

Noll's (1974) examination of factors that influence demand was the seminal work in this area. Noll's study of baseball, basketball, football, and hockey found that team quality, ticket price, number of star players, population, and per capita income were all significant factors in determining attendance. Other recent studies have had similar results analyzing the effects of the variables previously mentioned (DeSchriver, 1999; Jenson \& DeSchriver, 2002; Pan, Zhu, Gabert, \& Brown, 1999).

Several themes have emerged from the literature in this area. According to the majority of models, team quality characteristics (i.e., winning percentage, games back in the standings, championships, and playoff appearances), population, per capita income, stadium age, stadium capacity, and ticket price are significant determinants of attendance. The importance of the previously mentioned variables is well documented. However, there has been limited research on the impact of team composition and roster turnover on attendance.

\section{Player Composition Effects on Demand}

In their study of team racial composition in the NBA, Burdekin and Idson (1991) found that there was an increase in attendance when the racial composition of the team matched that of the community. The empirical findings showed that racial composition of a certain population would have strong influence on the structure of the team roster. The ratio of white players on the team to that in the population exerts a significantly positive effect on attendance. In addition, the results suggest that it is the racial composition of the starters that have a significant impact on attendance.

Results of the regression models support the primary hypothesis that the link between racial structure of teams and racial structure of team market areas may be logical in terms of profit maximization. This study was not designed to analyze the difference in roster turnover or player change. However, the results show that roster composition does have an effect on demand. This study provides strong support for consumer preferences helping to shape the composition of teams in the NBA. Future studies regarding player composition can provide further evidence of the impact team composition has on attendance. In addition, it is important to understand whether or not regular changes in team composition have any effect on demand in the NBA.

Rivers and DeSchriver (2002) examined the effect of star players and payroll distribution on attendance. The authors found that a star player must have made a significant contribution to the team in the current year in order to have a significant effect on attendance. Those star players who do not impact team success in a given year will have little or no effect on attendance. In addition, the authors found that higher payroll will significantly increase attendance. However, the relationship between intra-team payroll variation and attendance was negative. The results suggest Major League Baseball teams with a more balanced payroll distribution have better attendance than those who pay one or two players most of the team payroll. Star players may increase season ticket sales in the short term; however, in the long term a more balanced roster will positively impact attendance. Previous studies (Noll, 1974; Whitney, 1988) have proven a strong relationship between on-field success and attendance. When 
the balance of the payroll distribution shifts to one or two players this can decrease the winning percentage and create a negative effect on attendance.

Nourayi's (2006) examination of profitability and the NBA used benchmarking methods to compare measures for a group of "inferior" NBA teams with those of the top-performing teams in the league. The purpose of such comparisons was to identify team attributes that help a team increase its winning percentage. Because a team's performance depends on players and coaching staff, processes such as players and coaching personnel selections greatly influence long-term strategic concerns. These concerns include support of local businesses and government, as well as the stability of the franchise. Results of this study indicate that because the team's winning percentage has a significant impact on attendance, it is most profitable for NBA teams to make roster changes in an effort to improve overall team performance. This will increase attendance and profitability over time.

There is only one previous study that focused specifically on the effects of roster turnover on attendance. Kahane and Shmanske (1997) examined roster turnover effects in MLB. The results showed that winning percentage had a positive impact on attendance. An extra point in a team's winning percentage increased annual attendance by about 32,000 fans in the current year and 25,000 fans the following year. Income, population, and a new stadium were also found to positively impact attendance. Ticket price was found to have a negative effect on attendance.

The main variable of interest, roster turnover, was measured in two distinct ways. Player turnover focused on the percentage of players on the team who played in $60 \%$ of games in a given season and who were not on the roster the following season. Payroll turnover measured the percentage of payroll leaving the team from one season to the next. Both of these variables were found to have a significantly negative effect on attendance. Teams lost, on average, 27\% of their players in each year examined. For each percentage point loss, yearly attendance decreased by about 6,000 to 12,000 fans. In addition, the loss of a productive player (without the gain of an equally or more productive player) led to a decrease in team quality factors. This ultimately had a further negative effect on attendance.
The Kahane and Shmanske (1997) study focused specifically on roster turnover in Major League Baseball. There has not been any research conducted to examine the importance of this variable in other leagues. The fan bases for different sports and leagues may have unique characteristics. The variables that affect demand in Major League Baseball may have a different impact in other professional sports. An examination of the impact roster turnover has on demand in other leagues will help sport managers gain a more complete understanding of the effect of player movement.

\section{Methodology}

\section{The Demand Model}

A demand model was used to measure the effect of roster turnover on demand in the NBA. The model was created through an analysis of the previous literature on the factors that affect demand. In addition to roster turnover, 11 explanatory variables were used to control for other factors that may impact the variability of attendance in the NBA.

This model is unique compared to previous models that have examined the factors that affect demand in the NBA by focusing on the impact of roster turnover. The following section defines the dependent variable, the variable of interest (roster turnover), and each of the 11 explanatory variables that make up the model.

\section{Dependent Variable}

Attendance (ATTEND)_The total annual attendance at home games for each of the 30 NBA teams that were in the league from the 2000-2001 season to the 2004-2005 season.

\section{Variable of Interest}

Roster Turnover-The main variable of interest was measured in two distinct ways based on the previous work of Kahane and Shmanske (1997) in Major League Baseball. Player Turnover (PTURNOVER) measured the percentage of players on a team who played in $60 \%$ of games in a given season and who were not on the roster the following season. Initially, player turnover was broken into two variables. One variable measured total roster turnover and the other variable looked at roster turnover only from players who appeared in at least $60 \%$ of games. 
Morse, Shapiro, McEvoy, Rascher

There was no significant difference in the impact of these variables, so the $60 \%$ cutoff was implemented to highlight the impact of turnover from the players who regularly appeared in games during a given season, and to compare the results to the previous study on MLB.

Salary Turnover (STURNOVER) measured turnover as the proportion of a team's payroll that does not return the next season. This variable essentially weighted players based on their salary to determine the turnover impact of significant shifts in payroll from season to season. It allows for the estimate of turnover for higher quality players (proxied by salary). The use of these two variables helps further explain any impact roster turnover may have on demand.

\section{Explanatory Variables}

1. Previous Year's Attendance (PREVATT)—a lagged attendance measure to capture the change in attendance from one season to the next. It is important to understand how roster turnover affects this change for a franchise from one season to the next.

2. Current Season Winning Percentage (CURWIN) - the winning percentage for a team in a given season. Current winning percentage has been shown to have a positive relationship with attendance (Kahane \& Shmanske, 1997; Noll, 1974; Scully, 1974).

3. Previous Winning Percentage (PREVWIN) - the winning percentage for a given team in the previous season. The winning percentage for a team in a previous season can also have an effect on the current season's attendance due to the fact that fans identify the recent performance of a team and relate that to current success. Previous winning percentage has been shown to have a positive relationship with attendance (McEvoy et al., 2005; Kahane \& Shmanske, 1997).

4. All-Star Players (ALLSTAR) - the number of players on a given team that made the all-star game in the previous season. Rivers and DeSchriver (2002) found that a player who has made a significant contribution to a team will positively affect attendance. Fans can be attracted to the status of specific players in addition to the overall success of the team.

5. History (HIST) - the number of league championships a team has won over the history of the franchise. Many teams have a tradition of success that is acknowledged by fans. It is impor- tant to understand the impact of a team's history of success on attendance.

6. Population (POP) - the population, as reported by the U.S. Census Bureau, of the county where a team plays. This variable has been used in numerous demand studies (Baade \& Tiehen, 1990; Kahane \& Shmanske, 1997; Pan et al., 1999). Population is expected to have a positive effect on attendance as teams in larger markets have more potential customers.

7. Per Capita Income (INCOME)—Per capita income was used to measure potential purchasing power in a team's area. The effect of per capita income has been mixed in previous demand studies; however, it has been shown to have an impact on attendance (Baade \& Tiehen, 1990; Kahane \& Shmanske, 1997; Noll, 1974; Scully, 1974).

8. Average Ticket Price (TIXPRICE) - the average ticket price for a game in a given season. The majority of demand studies have used some form of ticket pricing to examine its effect on attendance (Kahane \& Shmanske, 1997; McEvoy et al., 2005; Noll, 1974; Pan et al., 1999; Scully, 1974).

9. Local Major Sport Competition (SUB) - the number of major sports teams (i.e., NFL, NHL, and MLB) that are located in the same city or metropolitan area and that present direct competition for NBA teams. Previous studies have found that cities with more competition for the sports entertainment dollar have lower demand for their product (Rascher, Brown, Nagel, \& McEvoy, in press; Pan et al., 1999).

10. New Arena (ARENA) - a dummy variable that was equal to one if the arena had been built in the past five years. Previous studies have found that a new arena or stadium has a positive effect on attendance (Kahane \& Shmanske, 1997; McEvoy et al., 2005; Noll, 1974).

11. Conference Affiliation (CONF) - a dummy variable that was used to differentiate between the Eastern and Western Conferences in the NBA.

12. Division Affiliation (DIV) - a dummy variable that was used to identify the division that a specific team competes in. There are divisional rivalries and certain divisions that are more competitive in the NBA. This factor may also have an impact on attendance.

\section{Sample}

Data were collected for five seasons (2000-2001 to 20042005) on each team that competed in the National 
Basketball Association. Because of data limitations, the Charlotte Bobcats were omitted from the data set. (The team's first year of competition was 2004-2005.) Also, only two years of data were used for the New Orleans Hornets. (They competed in Charlotte during the 20002001 and 2001-2002 seasons.) Only three years of data were used for the Memphis Grizzlies. (They competed in Vancouver during the 2000-2001 season.) The Eastern Conference had a higher average total season attendance during the five years examined (699,969 average season attendance). In addition, the Central Division of the Eastern Conference had the highest average season attendance of any division during the five years examined (727,307 average season attendance). Overall, the sample size was $N=140$.

\section{Procedures}

Data on the variables in the demand model were collected from a variety of sources. Attendance data were collected from ESPN.com and NBAhoopsonline.com. Both roster turnover and salary turnover data were collected from ESPN.com and USAToday.com. Winning percentages (both current and previous), all-star appearances, team history, league and conference affiliation, local competition, and arena age data were all collected from ESPN.com and NBA.com. Ticket price data were collected from NBA.com. Population and per capita income data were both collected from the U.S. Census Bureau.

\section{Statistical Design}

A multiple linear regression equation was developed to examine the relationship between roster turnover and season attendance, while controlling for other potentially confounding variables in the model. Initially, a variety of different regression equations were tested to generate the best fitting model. Because of the nature of NBA demand, there are a number of sellouts. During the five NBA seasons examined, there were 18 occasions in which a team sold out all of its home games for the entire season. In these situations, the level of demand can be higher than attendance; however, because of the capacity constraints, the actual level of demand cannot be measured. Ordinary least squares (OLS) regression measures the variability of attendance explained by the model. However, OLS regression assumes that there are no constraints on any of the variables. Sellouts are common in the NBA and the capacity of a stadium can prevent the true level of demand from being determined. Sellouts imply that the level of demand was higher than the capacity of the stadium (Rascher, McEvoy, Nagel, \& Brown, 2007). Through the use of censored regression, the empirical model can forecast the level of demand above and beyond the capacity constraints of NBA arenas. The censored regression model takes into consideration the capacity constraints by forecasting the level of demand beyond capacity, using information from both the uncensored variables and seasons that were not sold out. Censored regression can provide a better understanding of the relationship between roster turnover and attendance in the NBA, and therefore it was the optimal model for this analysis.

All of the multiple linear regression assumptions (Linearity, Independence, Normality, and Equality of Variances) were examined. Descriptive statistics, residual plots, and statistical tests for normality and equality of variances showed that none of the assumptions were violated in the regression equation. In addition, potential multicollinearity issues within the model were examined. Both variance inflation factors and tolerance statistics were examined for multicollinearity issues. The results suggested there were no multicollinearity issues in either of the final regression equations used in the analysis. A significance level of 0.05 was established $a$ priori in analyzing the regression models and related variable correlations.

\section{Results}

Table 1 provides the descriptive data for all the continuous variables used in the regression equation. The results showed that the NBA teams sampled between the 20002001 and 2004-2005 seasons had an average total home attendance of 700,086 with a standard deviation of 92,707 . There was a small degree of variability in the sample compared to similar demand studies in other professional sports. On average, about one-third of teams' rosters changed each season. The average player turnover of $36.2 \%$ and average salary turnover of $36.7 \%$ were almost identical. Interestingly, there were instances in which a team did not have any turnover and where a team had over $88 \%$ of its roster change. 
Morse, Shapiro, McEvoy, Rascher

Table 1. Descriptive Statistics

\begin{tabular}{|c|c|c|c|c|c|}
\hline Variable & Variable Description & Mean & $\begin{array}{l}\text { Standard } \\
\text { Deviation }\end{array}$ & Minimum & Maximum \\
\hline ATTEN & Game attendance & 700086 & 92707 & 471374 & 913176 \\
\hline PTURNOVR & Player turnover & .362 & .187 & 0 & .889 \\
\hline STURNOVR & Salary turnover & .367 & .207 & .009 & .985 \\
\hline PREVATT & Previous year's attendance & 694952 & 96740 & 471374 & 913176 \\
\hline CURWIN & Current winning $\%$ & .506 & .144 & .159 & .756 \\
\hline PREVWIN & Winning \% from the previous year & .504 & 147 & .183 & .817 \\
\hline ALLSTAR & \# of All-Stars on roster & .757 & .785 & .0 & 3 \\
\hline HIST & \# of championships & 2.11 & 3.89 & 0 & 16 \\
\hline POP & Home team's county population & 2902189 & 2469741 & 572059 & 9519338 \\
\hline INCOME & Home team's county per capita income & 24612 & 5110 & 18400 & 42922 \\
\hline TIXPRICE & Average ticket price & 45.77 & 11.88 & 26.38 & 91.15 \\
\hline SUB & Local sport competition & 2.56 & 1.81 & 0 & 7 \\
\hline
\end{tabular}

Note: $\mathrm{n}=140$

Table 2. Variable Correlations with Attendance

\begin{tabular}{ll}
\hline Variable & Attendance \\
PTURNOVR & -.072 \\
STURNOVR & -.047 \\
PREVATT & $.789^{\star}$ \\
ALLSTAR & $.336^{\star}$ \\
CURWIN & $.391^{\star}$ \\
PREVWIN & $.340^{\star}$ \\
HIST & $.170^{\star}$ \\
POP & $.293^{\star}$ \\
INCOME & .058 \\
TIXPRICE & $.178^{\star}$ \\
CONF & -.001 \\
DIV & -.106 \\
ARENA & -.100 \\
SUB & -.013 \\
\hline
\end{tabular}

${ }^{*}$ Correlation is significant at the .05 level. $n=140$

Other important descriptive findings included average population, per capita income, and ticket price. The average population in the sample was $2,902,189$ with a mean per capita income of $\$ 24,612$. The average ticket price of all games in the sample was $\$ 45.76$. Finally, the average amount of all-star players on the teams sampled was 0.75 .

Table 2 provides correlational data for each of the independent variables in the study and attendance. Seven of the 14 independent variables were significantly correlated to attendance at the 0.05 level. The independent variables that correlated most strongly with attendance were previous attendance $(r=.787)$, current team winning percentage $(r=.391)$, previous team winning percentage $(r=.339)$, and number of all-star players on the roster $(r=.336)$. It is important to note that neither measurements for roster turnover (player turnover and salary turnover) were significantly correlated with attendance.

\section{Censored Regression}

Table 3 summarizes the results from the censored regression analysis. Out of 140 observations, only 18 teams completely sold out all of their home games in a given year. The estimate of attendance for these 18 observations is based on the predicted values from the censored regression. The censored regression model was found to be significant with a log-likelihood statistic of 113.631 .

As displayed in Table 3, the variables PREVATT ( $p=$ $<.001)$, CURWIN $(p=<.001)$, PREVWIN $(p=.028)$, $\operatorname{ALLSTAR}(p=.029), \operatorname{HIST}(p=.017), \operatorname{ARENA}(p=.044)$, 
Table 3. Censored Regression Results (Dependent Variable = Season Attendance)

\begin{tabular}{lrccc}
\hline Variable & Estimate & Standard Error & Chi-Square Statistic & P-value \\
PTURNOVR & -.0311 & .0580 & .29 & .5920 \\
STURNOVR & .0696 & .0470 & 2.20 & .1382 \\
PREVATT & .001 & .0012 & 98.94 & $<.0001$ \\
CURWIN & .3415 & .0654 & 27.26 & $<.0001$ \\
PREVWIN & .1550 & .0742 & 4.36 & .0368 \\
ALLSTAR & .0313 & .0128 & 6.02 & .0142 \\
HIST & .0059 & .0023 & 6.60 & .0102 \\
POP & .0043 & .0009 & 4.00 & .0456 \\
INCOME & .001 & .0000 & 1.02 & .3119 \\
TIXPRICE & .0003 & .0009 & .10 & .7575 \\
CONF & -.0060 & .0434 & .02 & .8895 \\
DIV & .0304 & .0552 & .30 & .0439 \\
ARENA & .0628 & .0312 & 4.06 & .0089 \\
SUB & -.0224 & .0085 & 6.87 & \\
\hline
\end{tabular}

Note: There were 18 censored observations in the sample.

POP $(p=.0456)$, and SUB $(p=.008)$ were found to be significant variables within the censored regression model. All of these variables except SUB (local sport competition) had a positive relationship on attendance. Previous attendance explained the most variability in attendance. This was expected due to the high correlation between current and previous attendance. It was an important variable in the model because it helped to examine the effect of roster turnover on the change in attendance from year to year. Current winning percentage, previous winning percentage, population, and playing in a new arena were all positively related to attendance. The significance of these variables was consistent with previous demand studies (Kahane \& Shmanske, 1997; McEvoy et al., 2005; Noll, 1973). Local sport competition was the only variable that had a significantly negative impact on attendance. For each additional major professional sports team in a city or metropolitan area, the local NBA team saw an associated decrease in attendance by about $2 \%$. This finding is consistent with recent research showing that NBA and minor league hockey teams saw an increase in attendance of approximately 2\% during the NHL lockout in 2004-2005 (Rascher et al., in press). Another interesting finding was the significance of the all-star variable. It appears that the number of all-stars from the previous year that stay on the roster positively affects attendance. Finally, team history appeared to have a positive impact on attendance. The tradition built over time through NBA championships appears to have an effect on attendance.

Neither the player turnover nor the roster turnover variable was significant in the model. In general, the findings support the notion that roster turnover did not have a significant effect on attendance in the sample examined. This is contradictory to the results in the previous MLB study. Taking the capacity constraints into account may have had an effect on the amount of variability explained by roster turnover in the censored regression model. Finally, other control variables such as population, income, and ticket price were not found to be statistically significant in the model. These variables were all found to be significant in the MLB model but appeared to play only a minor role in determining attendance in the NBA.

\section{Discussion}

The purpose of this study was to develop a model to measure the effect on demand due to roster turnover and 
Morse, Shapiro, McEvoy, Rascher

changes in the composition of NBA teams. The model incorporates additional variables based on previous literature to help explain a significant portion of the variation in NBA attendance. Current winning percentage, previous winning percentage, attendance from the previous year, the number of all-stars on the roster, county population, local sport competition, and the championship history of the organization were all found to be significant predictors of attendance in the model. However, this study's results do not support the findings of previous research in terms of player movement. The main variable of interest, roster turnover, was not found to be a significant predictor of attendance. This was contradictory to Kahane and Shmanske's (1997) previous study on roster turnover in MLB. In addition, a censored regression model was used to account for capacity constraints. The censored regression equation may have accounted for some of the differences in findings from previous studies.

\section{Roster Turnover Effects}

Both variables used to measure the effect of roster turnover on demand in the NBA were found to be statistically insignificant. Contrary to popular opinion, the findings showed a distinct difference in the effect of roster turnover in the NBA in comparison to MLB. This difference can be attributed to various factors. One possible explanation for the difference between the MLB study and the NBA study is the fact that consumer motivation and fan base may differ from one professional league to another. Baseball is known to have a strong tradition and rich history. Some baseball fans have a purist mentality and may be negatively affected by the aspect of player movement. The sociodemographic variables and internal motivation to attend sporting events tends to vary across different sports as well. Spectators will have motivations to attend sporting events based on their individual preferences, experiences, and values (Wann, Schrader, \& Wilson, 1999).

This study provides evidence that demand for the NBA is not necessarily affected by player movement provided the team continues to have success. NBA fans may be more willing to except roster changes in the interest of winning, where MLB fans may have a stronger affinity for specific players. Ultimately, leagues and individual teams must have a complete understanding of the unique sociodemographic makeup and attitudes of their fans in relation to player movement in order to market their team effectively.

Another possible explanation is the effect of the economic invariance principle on the NBA. Despite a team losing a star player, the economic invariance principle explains that a star player will be replaced by a player or players of similar salary and abilities. In most cases, teams change their rosters to improve the overall quality of the team (Nourayi, 2006). If fans believe that current player movement is done in an effort to improve the team, they may look more favorably upon roster turnover. A player whom fans appreciate may leave the team, but if a more talented player replaces him, then fans may accept the move. This notion supports Nourayi's (2006) findings that less successful NBA teams make roster changes in an effort to emulate the most successful teams. Player movement through trades could be seen as a positive organizational move and therefore appreciated by those who support the team.

This type of roster turnover is an attempt to increase the team's winning percentage. This study shows that winning percentage has a significantly positive effect on demand at NBA games. The findings support this notion by the fact that the all-star variable was found to have significantly positive effect on attendance as well. The general player movement may not have an impact on fans' decisions to attend NBA games; however, players who make a major contribution to the team can affect demand. This is supported by Rivers and DeShriver (2002), who found that a star player who makes a contribution that increases the team's on-field performance will have a significantly positive impact on attendance.

In addition, players on a current roster are generally known, where new players are exciting and the possibilities for winning become greater in the minds of fans. Unless a team has won a championship there is room for improvement. Therefore, any change in roster might spark the interest of fans and make them more likely to attend games in order to evaluate the new players on the roster and the overall success of the team.

A third possible explanation for this finding is that fans have become more accustomed to the increase in player 
movement (Sanderson \& Siegfried, 1997), which deemphasizes the importance of roster continuity. Sanderson and Siegfried note that professional leagues with draft systems could take advantage of players with regional popularity; however, they choose not to. Their conclusions provide further evidence that ownership is motivated by winning rather than individual player popularity. This could be the result of free agency in the market place. In Maxcy and Mondello's (2006) study on competitive balance in Major League baseball it was confirmed that free agency had increased the rate of roster turnover while also improving some aspects of competitive balance.

\section{Censored Regression Model}

The use of censored regression may have also accounted for the findings. The majority of demand models in relation to sport attendance do not use a censored regression model to account for capacity constraints. Sellouts will decrease the amount of variability in attendance because demand may be higher than the capacity of certain arenas. The censored regression model estimates the level of demand beyond the capacity constraints and therefore is likely to have an effect on all variables in the model. An examination of this model by using an OLS regression equation did not change the significance of roster turnover. However, there were only 18 sellouts in the sample examined. Additional samples may have a greater effect on the results of the censored regression model. It is important to understand the impact that the censored regression model can have in situations that warrant its use.

\section{Limitations}

A primary limitation of this study is the lack of generalizability beyond the population of the NBA basketball games played during the 2000-2001 to 2004-2005 seasons. The results of this study cannot be generalized beyond this group of subjects without raising external validity concerns. Second, time must be considered when this study is compared to the previous study conducted in MLB. Cultural changes in society along with changes in league rules may impact consumer behavior, which can alter results. Fans have become more comfortable with player movement over time (Sanderson \& Siegfried, 1997), and this may have a considerable impact on attendance.

\section{Implications for practitioners}

Professional sports are revenue-motivated organizations in a competitive entertainment industry. Mullin, Hardy, and Sutton (1993) indicated that professional sports executives manage their business in much the same way as corporate executives. From a player composition standpoint, professional team executives will always attempt to put a roster together that will increase winning percentage which has been shown to increase demand. In the NBA specifically, team success has a stronger impact on fan support than team composition. The results of this study can help practitioners who are trying to make player personnel moves through the draft, trades, and free agency in an effort to improve their roster. It is important to understand the potential affect this turnover has on the demand to attend games. When an organization is improving the talent level on their roster, it must find players who are the best fit on the court and not worry about how player movement affects fan loyalty.

\section{Directions for future research}

There are a number of areas that warrant further investigation on the topic of roster turnover and demand. First, the results from the regression equations show the variables that impact demand in the NBA. However, this quantitative analysis was not able to explain why fans choose to attend NBA games. A better understanding of why this happens could be of great benefit to practitioners. This determination likely requires both qualitative and quantitative investigation of consumer behavior in this regard.

Another finding needing further examination is the differences in fan characteristics among leagues. A comparison of variables that impact demand among leagues will create a better understanding of the factors that have the most influence on attendance. In addition, testing the model in different leagues will enhance the validity of the instrument across different samples.

Finally, roster turnover must continue to be studied in different sports over different time periods. The impact of player movement and the importance of roster continuity are not completely understood. A future study could differentiate between roster turnover through free agency versus trading. Perhaps losing players to free agency as opposed to a trade has a differentiable effect. Free agency 
Morse, Shapiro, McEvoy, Rascher

may feel like a loss of control to the fans, but purposefully trading players to get other ones might be looked at more favorably. Further examination of player movement will help practitioners understand the attachment between players and fans. In addition, future research will help sport managers understand the role of roster turnover in specific professional leagues. Marketing strategies can then be tailored to account for this unique variable and maximize revenue to benefit the overall organization.

\section{References}

Baade, R. A., \& Tiehen, L. J. (1990). An analysis of Major League Baseball attendance, 1969-1987. Journal of Sport and Social Issues, 14(1), 14-32.

Ballard, C. (2006). The lost generation. Sports Illustrated, 105(16), 58.

Burdekin, R. C. K., \& Idson, T. L. (1991). Customer preferences, attendance and the racial structure of professional basketball teams [Electronic Version]. Applied Economics, 23(1B), 179-186.

Branvold, S. E., Pan, D. W., \& Gabert, T. E. (1997). Effects of winning percentage and market size on attendance in minor league baseball. Sport Marketing Quarterly, 6(4), 35-42.

Cordova, J. (2006, November 2). Activating sport sponsorships. Keynote speech presented at the Sport Marketing Association Conference, Denver, CO.

DeSchriver, T. D. (1999). Factors affecting spectator attendance at NCAA Division II football contests [Electronic version]. International Sports Journal, 3, 54-65.

ESPN (2007). NBA home page. Retrieved February 12, 2007, from http://sports-ak.espn.go.com/nba/index

Gorman, J., \& Calhoun, K. (1994). The name of the game: The business of sports. New York: John Wiley \& Sons, Inc.

Greenstein, T., \& Marcum, J. (1981). Factors affecting attendance at Major League Baseball II: A within-season analysis. Sociology of Sport Journal, 2(4), 314-322.

Hansen, H., \& Gauthier, R. (1989) Factors affecting attendance at professional sporting events. Journal of Sport Management, 3(1), 115-132.

Hoang, H., \& Rascher, D. A. (1999). The NBA, exit discrimination, and career earnings. Industrial Relations, 38(1).

Howard, D., \& Crompton, J. (2004). Financing sport ( $2^{\text {nd }}$ ed.). Morgantown, WV: Fitness Information Technology, Inc.

Jensen, P. E., \& DeSchriver, T. D. (2002). Determinants of spectator attendance at NCAA Division II football contests. Journal of Sport Management, 16(4), 311-330.

Kahane, L., \& Shmanske, S. (1997). Team roster turnover and attendance in Major League Baseball [Electronic version]. Applied Economics, 29(4), 425-431.

Maxcy, J,. \& Mondello, M. (2006). The impact of free agency in North American professional team sports leagues. Journal of Sport Management, 20(3), 345-265.

McEvoy, C. D., Morse, A. L. (2007). An investigation of the relationship between television broadcasting and attendance. International Journal of Sport Management and Marketing, 2(3), 222-235.

McEvoy, C. D., Nagel, M. S., DeSchriver, T. D., \& Brown, M. T. (2005). Facility age and attendance in Major League Baseball. Sport Management Review, 8(1), 19-41.
Mullin, B. J., Hardy, S., \& Sutton, W. A. (1993), Sport marketing. Champaign, IL: Human Kinetics.

Noll, R. G. (1974). Attendance and price setting. In R. G. Noll (Ed.), Government and the sport business. Washington, DC: The Brookings Institution.

Nourayi, M. M. (2006). Profitability in professional sports and benchmarking: The case of NBA franchises [Electronic version]. Benchmarking: An International Journal, 13(3), 252-271.

Pan, D. W., Zhu, Z., Gabert, T. E., \& Brown, J. (1999). Team performance, market characteristics, and attendance of Major League Baseball: A panel data analysis. Mid-Atlantic Journal of Business, 35(2-3), 77-91.

Pease, D. G., \& Zhang, J. J. (2001). Socio-motivational factors affecting spectator attendance at professional basketball games. International Journal of Sport Management, 2(1), 31-59.

Rascher, D. A. (1999). The optimal distribution of talent in Major League Baseball. In L. Hadley, E. Gustafson, \& J. Fizel (Eds.), Sports economics: Current research (pp. 27-45). Westport, CT: Praeger Press.

Rascher, D. A., McEvoy, C. D., Nagel, M. S., \& Brown, M. T. (2007). Variable ticket pricing in Major League Baseball. Journal of Sport Management, 21, 407-437.

Rascher, D. A., Brown, M. T., Nagel, M. S., \& McEvoy, C. D. (in press). Where did National Hockey League fans go during the 2004-2005 lockout? An analysis of economic competition between leagues. International Journal of Sport Management and Marketing.

Rivers, D. H., \& DeShriver, T. D. (2002). Star players, payroll distribution, and Major League Baseball attendance. Sport Marketing Quarterly, 11(3), 164-174.

Robertson v. NBA, No. 70 Civ. 1526. (NY 1975).

Rottenberg, S. (1956). The baseball players' labor market. The Journal of Political Economy, 64(3), 242-258.

Sanderson, A. R., \& Siegfried, J. J. (1997). The implications of athlete freedom to contract: Lessons from North America. Economic Affairs, 17(3), 7-13.

Scully, G. W. (1974). Pay and performance in Major League Baseball. The American Economic Review, 64(6), 915-930.

Shackelford, D. E., \& Greenwell, C. T. (2005). Predicting women's Division I sports attendance: An analysis of institutional characteristics [Electronic version]. Sport Marketing Quarterly, 14, 139-147.

Wann, D. L., Schrader, M. P., \& Wilson A. M. (1999). Sport fan motivation: Questionnaire validation, comparisons by sport, and relationship to athletic motivation. Journal of Sport Behavior, 22(1), 114-140.

Whitney, J. D. (1988). Winning games versus winning championships: The economics of fan interest and team performance, Economic Inquiry, 26(4), 703-724.

Zhang, J. J., Pease, D. G., Hui, S. C., \& Michaud, T. J. (1995). Variables affecting the spectator decision to attend NBA games. Sport Marketing Quarterly, 4(4), 29-39.

Zhang, J. J., Pease, D. G., Smith, D. W., Lee, J. T., Lam, E. T. C., \& Jambor, E. A. (1997). Factors affecting the decision making of spectators to attend minor league hockey games. International Sports Journal, 1(1), 39-53.

\section{Endnote}

${ }^{1}$ A "soft cap" allows teams to match an offer for their free agent giving them the opportunity to keep the player. The majority of NBA teams actually spend more on player payroll than the "cap" amount. 